(C) 2011 IEEE. Personal use of this material is permitted. Permission from IEEE must be obtained for all other uses, in any current or future media, including reprinting/republishing this material for advertising or promotional purposes, creating new collective works, for resale or redistribution to servers or lists, or reuse of any copyrighted component of this work in other works. 


\title{
A PROPOSED MODEL FOR SUCCESSFUL IMPLEMENTATION OF E-GOVERNMENT IN MALAYSIA
}

\author{
Bazilah A Talip \\ University of Kuala Lumpur, Malaysia \\ Dr. Bhuva Narayan \\ Queensland University of Technology, Australia
}

\begin{abstract}
This paper proposes a theoretical model for e-Government in Malaysia and addresses issues involved in its implementation. It presents three possible models including the Framework for Electronic Government (Grant \& Chau, 2005), the Three Pillars Framework (Georgescu, 2007) and The Grid-Group Theory from cultural studies (Douglas, 1996) and integrates and adapts them to the specific needs of the Malaysian environment.
\end{abstract}

\section{INTRODUCTION}

E-Government is an application that can reinvent how the government works as well as promote its interaction with citizens and businesses through improved connectivity and better access to information and services online (Siddiquee, 2008). It is informational, transactional, and collaborative. E-Government provides the connection between control, collaboration, culture, and technology - the engine of the e-Government in countries around the world. However, barriers still exist to the successful implementation of some of the Malaysian e-Government initiatives.

\section{MALAYSIAN CONTEXT}

Barriers involved in the implementation of effective e-Government initiatives in Malaysia include cultural, social, psychological, technological, and administrative barriers that are expressed in different degrees based on the dynamic within the government and its people. 


\subsection{Organisational factors}

Many government online services in Malaysia are ineffective due to a flood of broken links that are either non-functional, under maintenance or outdated (Siddiquee, 2008). To correct this, senior Government officials in Malaysia have been actively involved in the development of eGovernment with proper policies and code of practice. This is to reduce the gap between government and citizens, government and business, and government to government.

\subsection{Society and Culture}

The Malaysian government's public officials are drawn from various ethnic groups, cultures and beliefs although the majority are Islamic. Hierarchism, fatalism, individualism and egalitarianism has a huge impact on developing e-Government initiatives in Malaysia this fatalistic mentality, especially toward technology should be changed and improved in order to be more competitive globally. Hence the government has provided computer savvy facilities and training to its citizens with proper code of ethics.

\subsection{Technology and Interoperability}

E-government provides websites for online services accessible through computers or mobile technology. Citizens are now able to access the Internet through the increasingly ubiquitous

mobile phones. Some of the bigger technological issues involve interoperability across government agencies; a one-stop e-Government portal can only be achieved if back offices are interoperable (Choudrie \& Weerrakody, 2007) and this can only be achieved through an integration of data, processes, communications, and security (Tripathi, Gupta \& Bhattacharya, 2011).

\section{$2.4 \quad e-P a r t i c i p a t i o n$}

E-participation can be defined as the exploitation of ICT for engaging citizens to participate as much as possible to democratic procedures, interacting among them, as well as, with politicians 
and decision makers and providing them with the necessary information and appropriate rights in a way that reinforces their role in the decision making process (Masters, Macintosh, \& Smith, 2004). Some of the tools that can encourage e-Participation include chat rooms, blogs, online forums, ePetitions, eTax, eVoting, ePanels, ePolls, eCommunities, and eConsultation tools (Ergazakis, Metaxiotis, \& Tsitsanis, 2011). The Malaysian e-Government initiative needs to take these into its long-term planning.

\subsection{The mobile Government (m-Government)}

Malaysian e-Government initiatives use mobile applications extensively to enhance productivity termed M-Government. The use of mobile phones (or smart phones) helps the government to get closer to citizens in faster ways. Mobility services reduce data redundancies, human mistakes and speed effective (Roggenkamp, 2007). Services in different communication channels such as the m-teacher, m-clinic, m-neighbourhood and m-library should be introduced. Nonetheless, safety and security should be noted.

\subsection{MyKad, MyID, MyGovXchange and other services}

Malaysia is the first country in the world to use the Government Multipurpose Card which is known as MyKad that stores biometric information and facilitate transactions with government agencies and private organizations (Siddiquee, 2008). The government should ensure that personal information is protected and the card is accessible. Lack of access to appropriate systems, knowledge, and motivational support could explain the unsuccessful use of MyKad (Eynon, 2006).

The MyGovXchange client provides online payment systems and online forms submission (Hassan, 2010). This reduces corruption issues which further address the necessity of eGovernment initiatives especially for the Malaysian Government, which has compiled the National Key Result Areas (NKRAs) that includes strategies to combat corruption (PMO, 
2010c).

\subsection{Web 2.0 technologies}

Social media applications (blog tools, wiki tools, social networks, video sharing, mashups, and folksonomies) are used to provide additional channels to communicate closely with citizens. This allows people to share, discuss and vote for better ideas as well as respond to questions/topics of interest. This service is useful for business entrepreneurs to get information as well as for politicians to reach out to the public. Proper policy should be provided for privacy protection.

\section{THEORETICAL INSIGHTS}

Various frameworks have been developed to measure e-Government initiatives. Nevertheless, some existing theoretical frameworks in the area of e-Government are informative tools that can be used to develop and improve services of any nature. Three frameworks have been chosen in proposing a new model for the Malaysian e-Government:

- The generic framework for electronic government (Grant \& Chau, 2005),

- The three pillars structure (Georgescu, 2007), and

- The grid and group theory (Douglas, 1996)

\subsection{Generic Framework of e-Government}

The Generic framework for e-Government proposed by Grant and Chau (2005) is organised into two main sections as illustrated in Figure 1. The first section outlines Strategic Focus Areas (SFAs). The second division illustrates Key Functional Applications (KFAs). 


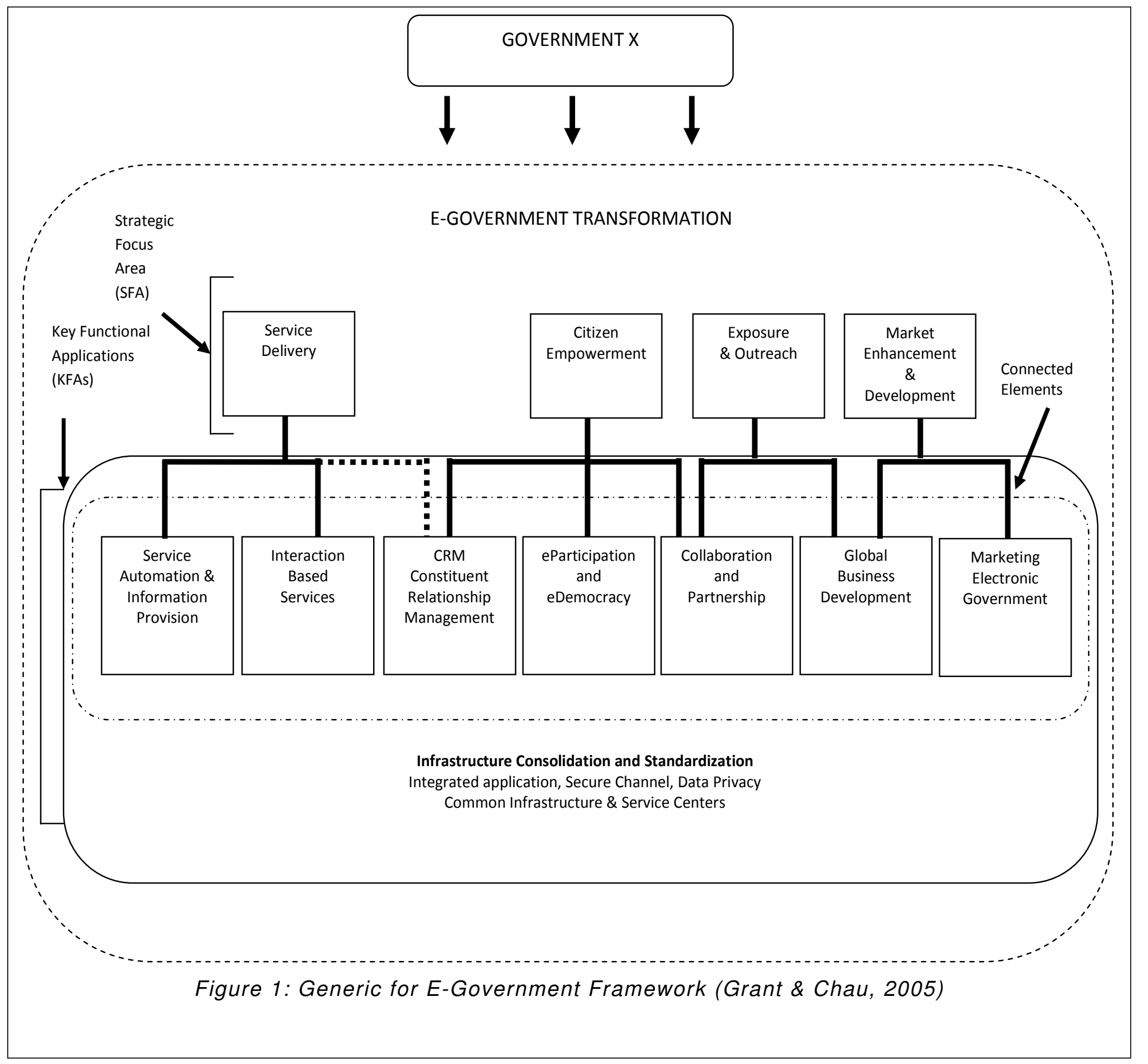




\subsection{Three Pillars of e-Government}

Georgescu's (2007) The Three pillars of e-Government (Figure 2) illustrate how public management and leadership can impact the e-Government initiatives' effectiveness.

1. Leadership

2. Organizational Structure

3. Process Management

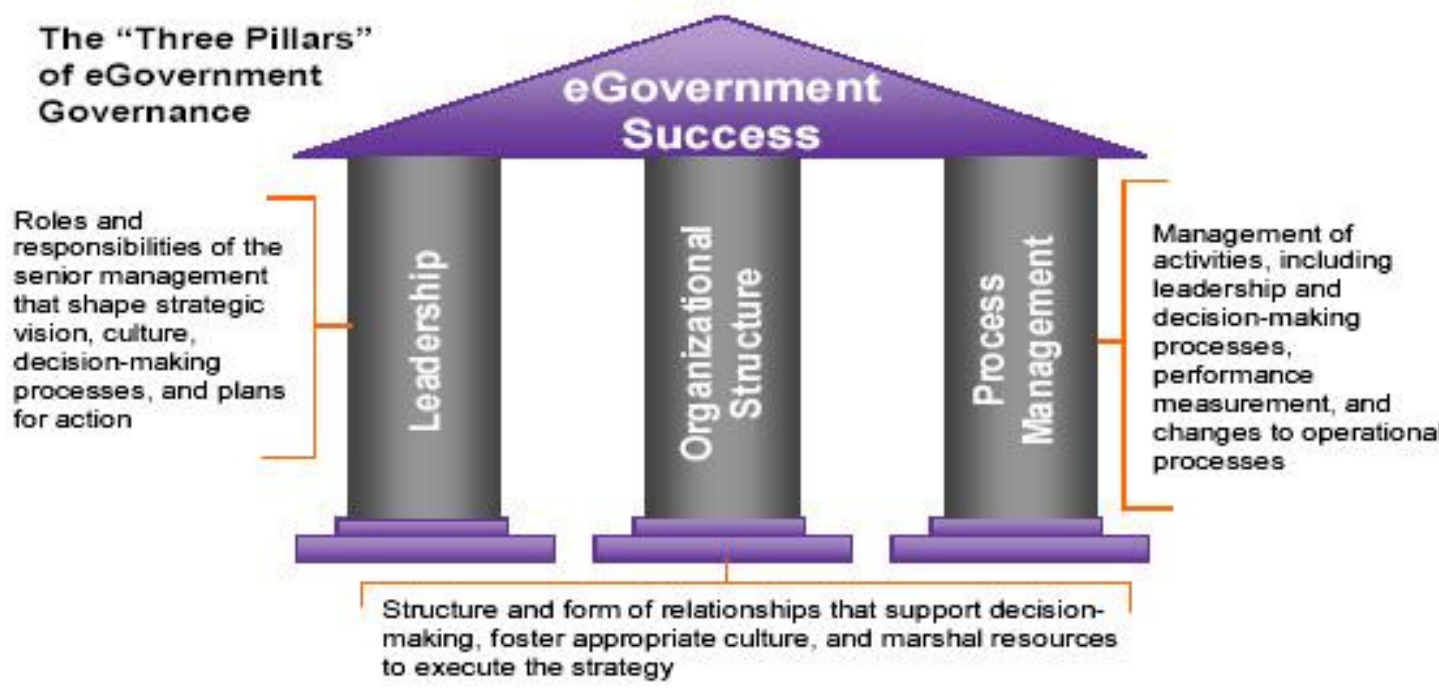

Figure 2: The Three Pillars of e-Government (Georgescu, 2007)

Studies have also revealed that lack of communication between public servants and citizens destroy e-Government initiatives (Siddiquee, 2005). Hence, incentives, appreciation, and recognition that reduce the effect of the bureaucratic and hierarchical system should be implemented to bridge this gap.

\subsection{Douglas' Group-Grid Theory}

The Douglas framework (Figure 3) outlines cultural influences that impact human behaviours and discusses cultural barriers and their impact on an individual's position within their social group (Douglas, 1996). 


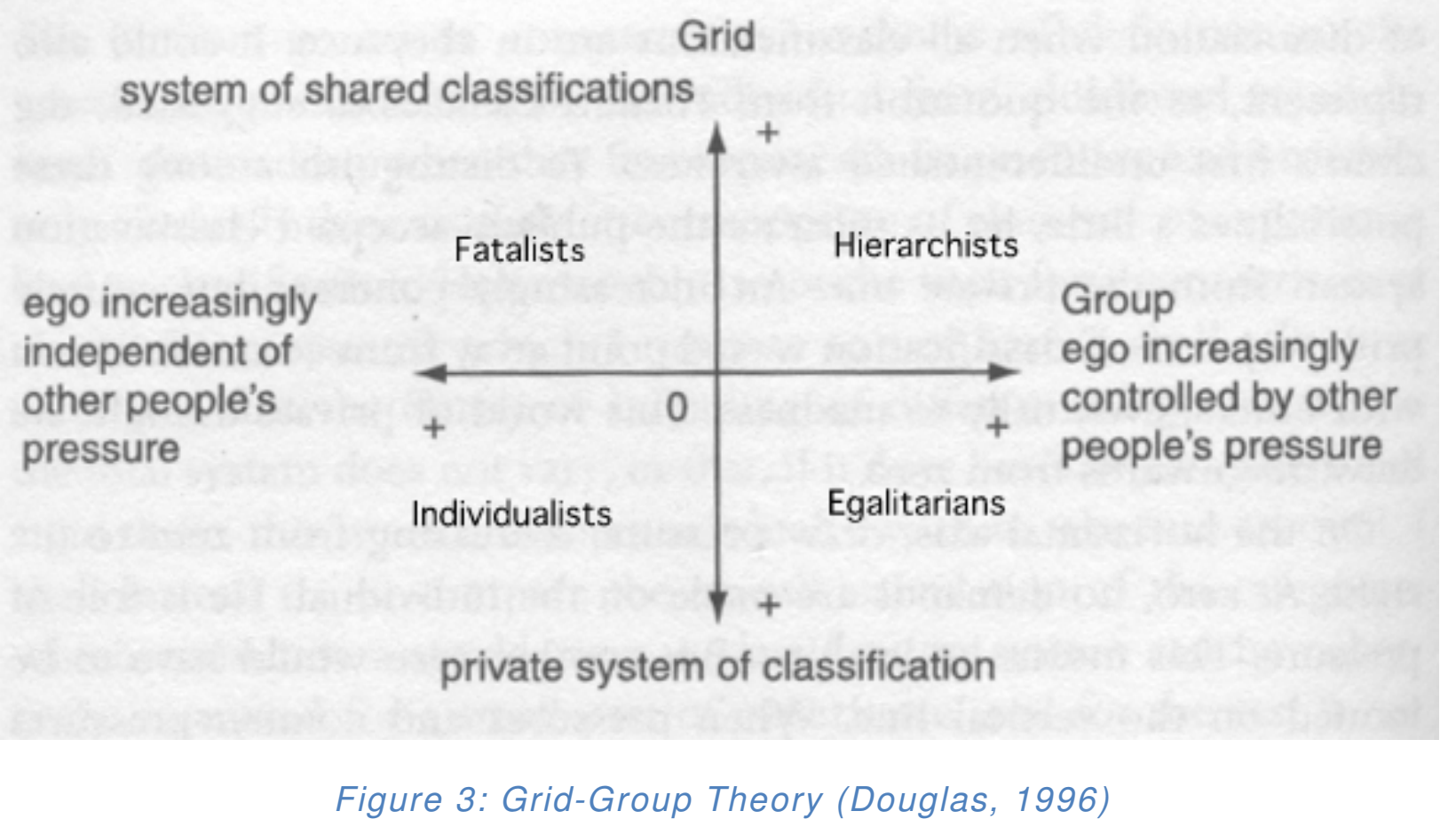

Hierarchy in Malaysia is ingrained both in society and in the Government which is hard to change especially in the line of succession for leadership positions (Siddiquee, 2006). Drake et al. (2004) and Titah and Barki (2008) found that subcultures also impact the effectiveness of eGovernment initiatives, and that scientific, political and bureaucratic subcultures can influence public administration to pursue e-Government services. Technology is important in improving the e-Government initiatives in Malaysia. It can help overcome fatalism and individualism, thus reducing the digital divide (Carter \& Weerakkody, 2008; Seng, et al., 2010).

\section{A PROPOSED E-GOVERNMENT FRAMEWORK FOR MALAYSIA}

This section proposes a new framework to develop e-government initiatives in Malaysia. It demonstrates the four key elements for improving e-Government initiatives. They are cultural diversity, collaboration, control, and technology. Research revealed that transformational and situational leadership could improve 
the initiatives by reducing the gaps between governments and citizens worldwide (Thompson\&Vecchio, 2009; Lee-Kelly, 2002; Bass, 1990). Public officials' engagement and communication channels for citizens significantly improve the eGovernment initiatives.

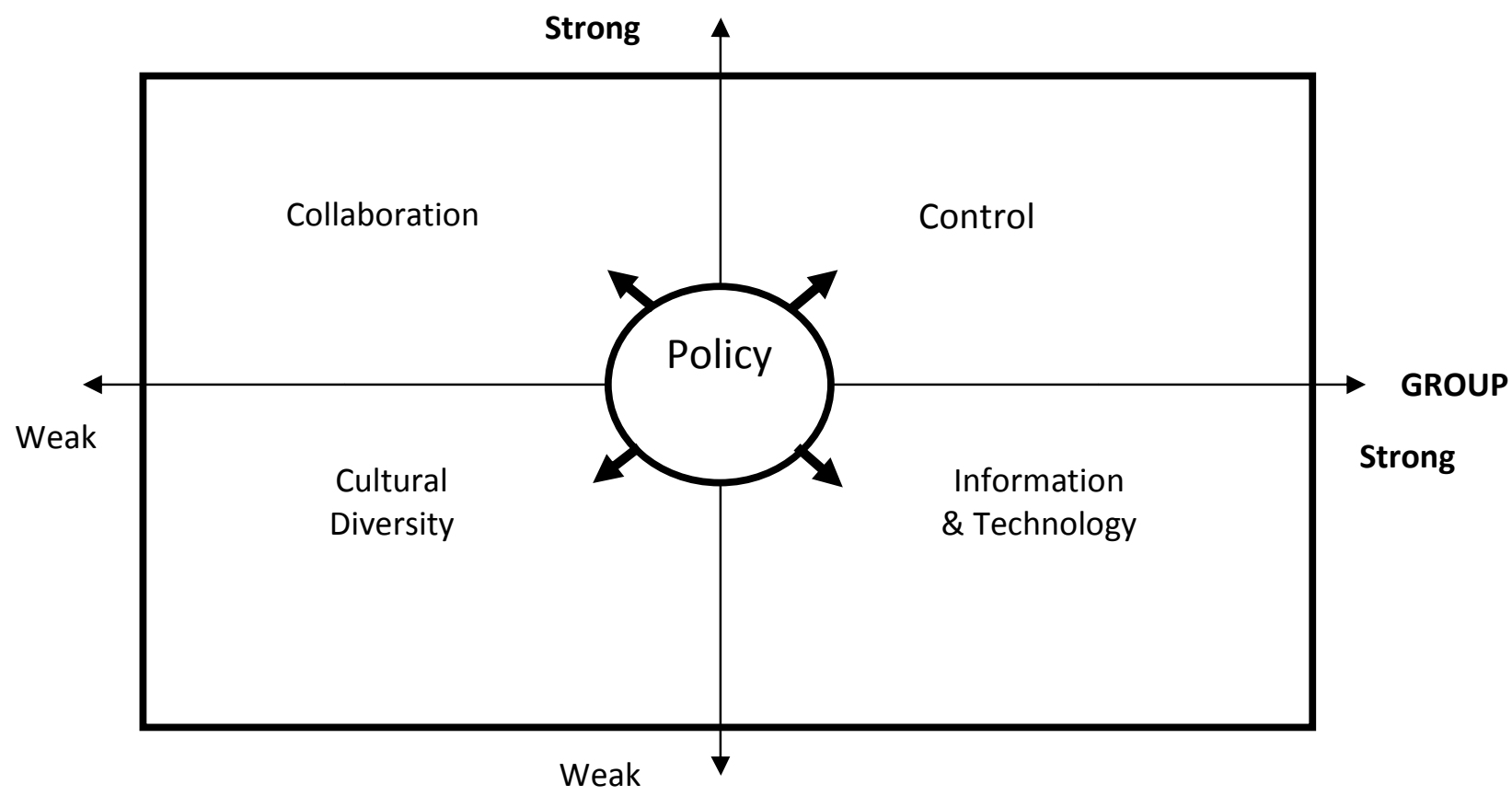

\section{Figure 4: A Proposed Framework for e-Government initiative Development}

The grid highlights the four weak and strong elements influencing the development of e-Government initiatives. Cultural diversity and information technology can negatively impact the effectiveness of e-Government. Engagement between the collaboration (public officials, interested stakeholders and citizens) and the control (the Malaysian Government and public administration) is highly influential in the development of e-Government services. The framework also demonstrates how control has a stronger influence than information technology. The third section discusses the policy lifecycle that is a key connector to the four elements in developing e-Government initiatives in 
Malaysia. It continues by defining how e-Government policy development directly influences eGovernment development. Policy development is vital to protect issues such as intellectual property, security, privacy, and copyright in developing e-Government initiatives worldwide.

Transparency and bureaucracy are also vital in policy development or eRulemaking in transforming e-Government to e-Participation successfully (Finger, 2010; Bertot et al., 2010; Vathanophas et al., 2008). Policy is crucial for governments worldwide to ensure trustworthiness of services to avoid damage. Lack of policy implementation impacts e-Government initiatives worldwide.

\section{CONCLUSION}

E-government initiatives provide better services to citizens, foreign investors, researchers, and industry collaborators for effective global competition. The three cultural and e-Government frameworks can be integrated and adapted to cater to the needs of the Malaysian e-Government.

All four elements - collaboration, control, cultural diversity and information technology - are vital in the successful development and implementation of eGovernment initiatives in Malaysia. Policy lifecycle and e-Rulemaking will ensure the four elements are connected to encourage e-Participation. It is vital for the government to continually develop and revise the policy and code of practice to ensure e-Government initiatives' productivity and public officials' performances as well as to gain stakeholders' satisfaction and communities' trustworthiness in e-Government. Situational and transformational leadership styles can change conventional management and reduce the gap between the government, citizens and 
businesses. Balancing the collaboration and control are vital in improving engagement between the Malaysian Government and citizens.

Additionally, research in e-Government will ensure that government services meet

citizen needs. Benchmarking the Australian and US e-Government is an approach to evaluate, improve and reengineer the Malaysian e-Government initiatives' productivity and encourage the public officials to play a key role (Jansen, et al., 2010; Taylor, et al., 2008; Siddiquee, 2005).

\section{References}

Bass, B. M. (1990). From Transactional to Transformational Leadership: Learning to Share the Vision. Organizational Dynamics, 3(18): 19.

Bertot, J. C., Jaeger, P. T., \& Grimes, J. M. (2010). Using ICTs to create a culture of transparency: E-Government and social media as openness and anti-corruption tools for societies. Government Information Quarterly. 27(3): 264-271.

Carter, L., \& Weerakkody, V. (2008). E-government adoption: A cultural comparison. Information System Front. 10(4): 473-482.

Choudrie, J., \& Weerrakody, V. (2007). Horizontal Process Integration in E-Government: the Perspective of a UK Local Authority. International Journal of Electronic Government Research. 3(3): 22-39.

Douglas, M. (1996). Natural symbols explorations in cosmology. New York: Vintage Books.

Drake, D.B., Stecklem, N.A., \& Koch, M.J. (2004). Information sharing in and across government agencies. The role and influence of scientist, politician and bureaucratic subcultures. Social Science Computer Review. 22(1): $67-$ 84.

Ergazakis, K., Metaxiotis, K., \& Tsitsanis, T. (2011). A State-of-the-Art Review of Applied Forms and Areas, Tools and Technologies for e-Participation. International Journal of Electronic Government Research. 7(1): 1-19.

Eynon, R. (2006). Breaking Barriers to e-Government. Digest of Electronic Government Policy and Regulation. 29: 205-217.

Finger, M. (2010). e-Government and Public Sector Reform: What Role for Government in eGovernment? The Innovative CIO and e-Participation in e-Government Initiatives. 43-48.

Georgescu, M. (2007). Challenges for E-Government Strategy. Revista Informatica Economica. 3(43):60-63.

Grant, G., \& Chau, D. (2005). Developing a Generic Framework for E-Government. Journal of Global Information Management. 13(1):1-30.

Hassan, M. S. (2010). Inovasi ICT Menjana Pertumbuhan Ekonomi [Innovation of ICT can help an economy growth] (translated by the author). Retrieved August 16, 2010, from http://www.pmo.gov.my/ksn/?frontpage/speech/detail/1617

Jansen, J., Vries, S. d., \& Schaik, P. v. (2010). The Contextual Benchmark Method: Benchmarking e-Government services. Government Information Quarterly.27 (3):213 $-219$. 
Lee-Kelly, L. (2002). Situational Leadership: Managing the virtual project team. Management Development. 21(6): 461-476.

Masters, Z., Macintosh, A., \& Smith, E. (2004) Young People and e-Democracy: Creating a Culture of Participation. Electronic Government. 3183(1):15-22.

PMO Office of the Prime Minister of Malaysia. (2010 c). Peoples' Support, Involvement Important To Ensure Success Of NKRA. Press release 28 January 2010. Accessed from http://www.pmo.gov.my/

Rogers, J. (2003). Councils rise to e-government challenge. Computer Weekly, 12. Retrieved from http://www.computerweekly.com/Articles/2003/09/02/196873/Councils-rise-to-egovernment-challenge.htm

Roggenkamp, K. (2007). "It's the Mobility Stupid". In I. Kushchu (Ed.), Mobile Government: An Emerging Direction in E-Government (pp. 60-83). New York: IGI Publishing.

Seng, W. M., Jackson, S., \& Philip, G. (2009). Cultural Issues in Developing E-Government in Malaysia. Behaviour \& Information Technology. 29(4):423-432.

Siddiquee, N. A. (2005). Public Accountability in Malaysia: Challenges and Critical Concerns. Journal of Public Administration. 28 (1): 107-129.

Siddiquee, N. A. (2008). E-Government and Innovations in Service Delivery: The Malaysian Experience. International journal of public administration. 31(7): 797.

Taylor, D., Hamid, F. A., \& Sanusi, Z. M. (2008). The Factors Impacting Managerial Performance in Local Government Authorities within an Islamic Cultural Setting. Journal of Applied Management Accounting Research. 6(2): 73.

Thompson, G., \& Vecchio, R. P. (2009). Situational leadership theory: A test of three versions. The Leadership Quarterly. 20(5): 837-848.

Titah, R., \& Barki, H. (2008). E-Government Research : Policy and Management In N. Donald (Eds.), E-Government Adoption and Acceptance: A Literature Review and Research Framework. Hershey, PA: IGI Global.

Tripathi, R., Gupta, M. P., \& Bhattacharya, J. (2011) Identifying Factors of Integration for an Interoperable Government Portal: A Study in Indian Context. International Journal of Electronic Government Research. 7(1): 64-88.

Vathanophas, V., Krittayaphongphun, N., \& Klomsiri, C. (2008). Technology acceptance toward e-government initiative in Royal Thai Navy. Transforming Government: People, Process and Policy. 2(4): 256-282. 